\title{
Diálogo-confrontación de saberes y negociación cultural: ejes de las pedagogías de la educación popular: una construcción desde el sur ${ }^{1}$
}

\section{Diálogo-confrontação de saberes e negociação cultural: eixos das pedagogias da educação popular: uma construção a partir do sul}

\section{Dialogue-confrontation of knowledge and cultural negotiation: a Southern production on axes of a popular education pedagogy}

Marco Raúl Mejía Jiménez ${ }^{2}$

\begin{abstract}
RESUMEN
Los desarrollos de la educación popular de nuestra América se han dado desde comienzos del siglo XIX cuando Simón Rodríguez propone al Consejo de Caracas desarrollarla en su educación. Cuando se revisan estos antecedentes, encontramos que una propuesta pedagógica siempre acompañó la dinámica de su constitución y este texto lo muestra en sus grandes hitos (nacientes repúblicas, universidades populares, escuelas de educación propia, pedagogías de la liberación), los cuales permiten mostrar la vitalidad invisibilizada pero presente en ellos. Hoy que la educación popular se propone como una apuesta para toda la sociedad y para todas y todos los educadores, el presente texto nos muestra cómo ese acumulado pedagógico es recuperado en
\end{abstract}

DOI: $10.1590 / 0104-4060.47205$

1 Programa Gubernamental Ciencia, Tecnología e Innovación - Ondas Colciencias y Planeta Paz, Expedición Pedagógica Nacional.

2 Programa Gubernamental Ciencia, Tecnología e Innovación - Ondas Colciencias y Planeta Paz, Expedición Pedagógica Nacional. Bogotá, Colombia. Calle 30 A 6-22 piso 27. E-mail: marcoraulm@gmail.com 
la propuesta actual fundada en el diálogo, la confrontación de saberes y la negociación cultural, haciendo posible una práctica de un ejercicio educativo que integra intraculturalidad, interculturalidad y transculturalidad y que teje lo común para seguir apostándole a la transformación de los mundos desde el reconocimiento de que somos humanamente diferentes, culturalmente diversos y seguimos viviendo en sociedades profundamente desiguales.

Palabras-claves: educación popular; confrontación de saberes; cultura.

\title{
RESUMO
}

O desenvolvimento da educação popular da nossa América ocorre a partir do início do século XIX, quando Simón Rodríguez propõe ao Conselho de Caracas implementar essa proposta na educação. Quando esses registros são revistos, se descobre que uma proposta pedagógica sempre tem acompanhado a dinâmica da sua construção e este texto pretende mostrar isso em seus marcos principais (repúblicas emergentes, universidades populares, escolas de educação, pedagogias da libertação), o que permite mostrar a vitalidade que é invisível, mas está presente neles. Hoje, quando a educação popular é proposta como uma aposta para toda a sociedade e a todas e todos os educadores, este texto nos mostra como esse arcabouço pedagógico reflete na proposta atual, fundada no diálogo, no confronto de saberes e na negociação cultural, tornando possível a prática de um exercício educativo que integra intraculturalidade, interculturalidade e transculturalidade e que produz o que é normal para continuar apostando na transformação dos mundos, reconhecendo que somos humanamente diferentes, culturalmente diversos e ainda continuamos a viver em sociedades profundamente desiguais.

Palavras-chave: educação popular; confronto de saberes; cultura.

\begin{abstract}
The development of popular education in our America has been produced since the beginning of the $19^{\text {th }}$ century, when Simón Rodríguez presents at the Council of Caracas a proposal to develop this in its education. When these records are reviewed, we find that a pedagogical proposal has always accompanied the dynamics of its construction, and this text shows it precisely in its major milestones (nascent republics, popular universities, schools of education, pedagogies of liberation), all of which allows to show the invisible but present vitality in them. Today, when popular education is proposed as a bet for all societies and educators (men and women), this text shows us how this pedagogical framework is recovered in the current proposal, founded on dialogue, confrontation of knowledge and cultural negotiation, making possible the practice of an educational exercise that integrates intraculturality,
\end{abstract}


interculturality and transculturality, which weaves what is common in order to carry on betting on the transformation of worlds, recognizing that we are humanly diverse, culturally dissimilar, and that we are still living in deeply unequal societies.

Keywords: popular education; confrontation of knowledge; culture.

La educación popular es parte de esa construcción común desde nuestras raíces, pero sin la madurez de la literatura o de otras expresiones, como la teología de la liberación, la comunicación popular o alternativa, la filosofía de la liberación, la descolonización y de muchas otras que se han desarrollado en nuestros contextos por dar forma a lo propio y en donde cada vez emergen más contenidos específicos ampliando sus desarrollos. Cada vez que nos acercamos a escribir sobre la educación desarrollada en estos lares, se nos cruza el reto de cómo seguir construyéndole un soporte cada vez más riguroso a nivel histórico, político, conceptual, metodológico, epistemológico y anclado en nuestra tradición y como es el caso de este escrito, lo pedagógico surgido y desarrollado desde nuestras particularidades, que nos diferencian para relacionarnos de otra manera y desde nuestras singularidades con lo eurocéntrico.

Desde esta mirada pudiéramos decir que en la matriz básica de la educación popular surgen las resistencias a las formas que intentan reducir la educación a la escolaridad y ésta a una única manera de concebirla y que se nos ha tratado de imponer para construir culturalmente el proyecto europeo en América, y ello a través de algunos de los padres de nuestra independencia y del poder colonial. Sobre esa disputa se construye el marco dominante, en el cual la educación y la escuela van a cumplir un papel central para asimilar mentes, cuerpos, deseos, estéticas, éticas, realizando un encubrimiento de nuestra historia, saberes, cosmogonías, epistemologías, que en muchos casos tuvieron que sobrevivir como resistencias, las cuales evitaron el total desmantelamiento de las expresiones culturales y sus raíces más profundas.

Esto hace visible cómo la educación y la escuela van a ser dos de los soportes principales para consumar la invisibilización de lo diferente y de las epistemes de lo pluriverso, logrando que en su aparente necesidad y unicidad se constituyan las formas que adquiere nuestro pasado en el momento del surgimiento de las nacientes repúblicas, como la única alternativa negando esas otras expresiones que pugnaban por emerger y que son invisibilizadas bajo la "bondadosa" idea de derecho para fundar las nuevas hegemonías culturales con las cuales se va a constituir una institucionalidad que unifica ontologías, espiritualidades, cosmovisiones y formas de vida. 
En ese sentido, en este texto rastrearé en un primer momento los aspectos pedagógicos del debate que gestores de algunas de las propuestas de otras educaciones a manera de resistencias interpusieron como actores de caminos propios $\mathrm{y}$, por lo tanto, considerados de los orígenes de la educación popular por cuestionar e impugnar el modelo educativo europeo, para constituir uno con particularidades propias, desde nuestras singularidades, dando forma también en esta esfera a otras pedagogías, metodologías, institucionalidades, convirtiendo el proceso educativo en un campo en disputa y en un ejercicio de autoafirmación capaz de dar cuenta de una manera propia de elaborar y vivir la vida y los conocimientos y saberes, lo cual permite expresar la intraculturalidad que da forma a la interculturalidad, que también disputa por fundamentar y darle forma en estos tiempos a ese sur que impugna, frente a una globalización (en singular) que impone una multiculturalidad de museo.

Ello quiere decir que la propuesta pedagógica en y desde la educación popular ha sido constituida desde las resistencias a las formas de control del poder en cada época, y al pregonarse como otro camino, con otras formas y contenidos, enfrenta la materialidad de la opresión y de la dominación, dándole vida a ese otro que niega y enfrenta e impugna la hegemonía en educación y pedagogía, tratando de visibilizarse como lo negado y que sobrevive en los procesos sociales y políticos que buscan darle identidad a las luchas pedagógico-políticas de estos tiempos.

En un segundo momento, trabajaré cómo la propuesta política de la educación popular se teje como un asunto pedagógico, en cuanto construye un entramado de diálogo y confrontación de saberes que, además de construir autonomía da fuerza a los procesos intra e interculturales, que nos llevan a través de su propuesta pedagógica y metodológica a construir los comunes impugnadores que exigen ir más allá del diálogo y reconocer las diferencias que excluyen, segregan y oprimen para ser confrontados para construir la acción transformadora y emancipadora, sentido profundo de la educación popular, trazando caminos de negociación cultural para darle forma y constituir lo común de los diferentes, y a la complementariedad de los proyectos de hoy que sueñan con otros mundos, haciendo de la pedagogía un asunto político para construir vida con sentido.

En tercer momento mostraré que es la realidad trabajada como escenario de actuación político-pedagógico la que hace que la educación popular no sea una receta metodológica y esté en permanente construcción. Ella se organiza y desarrolla con especificidad metodológica (dispositivos) desde las particularidades de los actores y de los ámbitos de actuación transformadora de ellos. Ése va a ser el sentido profundo de su construcción colectiva y siempre en reconstitución, nunca una fórmula, sino un sistema de mediaciones que a la vez que desaprende nos inventamos y transformamos nosotros la educación y el mundo. 


\section{La Pedagogía en la educación popular, un asunto con historia}

Hablar de búsqueda de una educación propia que rompa la mirada europea de ella, que parece un pensamiento muy original en estos tiempos para algunas corrientes, fue una constante en la disputa de las nacientes repúblicas, construyendo bloques que se acercaban más a una u otra posición, siendo emblemática la posición de Simón Rodríguez, maestro de Simón Bolívar. Aquél planteó la necesidad de que: "Los acontecimientos irán probando que es una verdad muy obvia, la América no debe imitar servilmente, sino ser original" (RODRÍGUEZ, 1975, p. 116) para no repetir a Europa en estos territorios y cuestiona el patrón sociocultural eurocéntrico, que al negar lo propio generaliza una superioridad institucional que homogeneíza, y para ello lo pedagógico como la práctica de esa concepción educativa va a ser ese instrumento privilegiado de homogeneización y subordinación intelectual, pensamiento en el cual también convergen en otros tiempos y lugares Artigas y Martí.

Es así como con muchos años se anticipó a la discusión pedagógica sobre la instrucción -la cual impregna toda su obra y que tiene como característica cuestionar e ir proponiendo alternativas. En este sentido, Simón Rodríguez propone un proyecto educativo que nos haga americanos y no europeos y una pedagogía que, a su decir, "sea para la vida" y nos permita ser constructores de ese proyecto y se anticipa con muchos años a la discusión entre enseñanza y aprendizaje, mostrándonos para esto último un camino muy diferente al del instruccionismo. Por ello afirma: "[...] el título de maestro no debe darse sino al que sabe enseñar, esto es, el que enseña a aprender, no al que manda aprender o indica lo que se debe aprender". (RODRÍGUEZ, 1975, p. 116).

Por ello, hizo de crítico sobre nuestra educación gestada por las élites criollas en todos los territorios que recorrió desde Venezuela a Chile, que tomaba por el camino de repetir a Europa y los rumbos que se tomaban los proyectos nacionales de educación en las nuevas repúblicas, lo cual le llevó a afirmar:

[...] lo primero es organizar una educación que forme ciudadanos, que prepare para vivir en república, que enseñe a trabajar para vivir y ejercer sus derechos y a cumplir sus deberes; sin eso no habría república, sino farsas de pronunciamientos y proclamas, letra muerta de construcciones y miseria y atraso para todos. (RODRÍGUEZ, 1975, p. 119). 
De igual manera, la cantera crítica de las universidades populares traen consigo en América Latina unas propuestas para enseñar de otra manera a como lo realizaban los europeos, pero por problemas de extensión dejaremos este tema para otro escrito. (PUIGGRÓS, 1984). ${ }^{3}$

También la escuela warisata ${ }^{4}$, con sus dos grandes creadores, Elizardo Pérez y Avelino Siñani ${ }^{5}$, en la cual desarrollaron en los años 30 del siglo anterior en Bolivia - una propuesta basada en el trabajo productivo y una pedagogía de la vida organizada con base en lo colectivo - y desarrollan el proyecto de ella en coherencia con el ¿en dónde? y ¿a quién?, van a formar y para ello reconocen como marco fundacional el reconocimiento de la herencia cultural de los pueblos que van a formar para que vivan en el presente y en coherencia con la filosofía andina, que ha sido negada por estereotipos que han inferiorizado lo propio, negando lenguas, cosmogonías y costumbres, produciendo una injusticia y desigualdad cultural, constituyendo un imaginario de asimetría cultural que homogeneíza, folklorizando lo propio.

Para ellos, el proyecto educativo era integral y la pedagogía debe ser realizada en coherencia con la filosofía que da identidad a los territorios que habita la escuela (PEREZ, 1985), cuestionando cómo la educación de la república a la vez que niega lo propio constituye la superioridad de lo otro que excluye. Por ello van a proponer una reorganización de la arquitectura, el espacio educativo, los contenidos, la metodología y todas las actividades que se realizan en el proyecto de warisata porque en ellas se debe dar forma al desarrollo de identidades y culturas, en cuanto es a través de ellas como la educación da forma a las naciones.

En ese sentido visibiliza y organiza educativamente un saber y conocimiento no sobre esas culturas sino desde ellas, como un ejercicio de conocerse a sí forjando identidades desde las particularidades que lleva a Pérez (1934) a decir: "[...] por eso el indio al realizar esta obra no ha hecho sino obedecer sus hábitos ancestrales de trabajo cooperativo".

En esa medida, la arquitectura va a ser neotiahuanacota para diferenciarla de la hispánica, la filosofía que orienta la escuela va a ser la visión del ayllu (comunidad-casa-familia externa) y su desarrollo una pedagogía de la vida que le dé forma a los cinco valores sobre los cuales se han constituido las instituciones ancestrales, y ellos son: la organización comunal basada en el autogobierno; la

3 Ver también de esta misma autora: De simón Rodríguez a Paulo Freire: educación para la integración latinoamericana. Bogotá: Convenio Andrés Bello, 2005.

4 Wari $=$ fuerza interior, sata $=$ sembrar o sembrado de la sabiduría.

5 Recordemos cómo Siñani era un indígena rebelde que fue castigado y preso por tratar de enseñar a los indígenas, lo cual era prohibido durante todo el siglo XIX y comienzos del XX en Bolivia. 
producción de la vida espiritual y material; las identidades propias; la solidaridad, y la reciprocidad.

Con este planteamiento daba forma educativamente a la disputa entre hacienda y comunidad, tan propia de las formas de colonialidad de nuestra América y que en la propuesta de warisata va a tomar especificidad en lo pedagógico y en lo metodológico. La organización del trabajo se hace desde el taller, como forma educativa del ser comunitario y constructor de procesos de intercambio y redistribución, a través del trabajo que es lo que da identidad al ayllu. En ese sentido, sus principios serían: Ayni (complementariedad), Minka (labor comunitaria), Ulaka (consejo de ancianos) y Machamaki (un solo esfuerzo).

En esta perspectiva, la organización del calendario escolar estaba adecuado a los tiempos de los procesos productivos y creativos y se interrelacionaban para que no existieran horarios. De igual manera, se hace una integración de áreas de desarrollo de la naturaleza y del miembro del ayllu en él, donde deben estar la plástica, la música, la educación física. La organización interna de la escuela está dirigida por el parlamento amauta, como forma de autogobierno que muestra cómo debe ser gobernada la nación. También era bilingüe y dio origen a lo que luego uno de sus principales impulsores, Carlos Salazar, denominaría el arte neo-indio ${ }^{6}$.

Recordemos cómo el fin de esta escuela fue la destitución de sus maestros y la persecución de quienes habían sido formados allí, descalificación que se hizo a nombre de la lucha anticomunista de los militares bolivianos. Como bien dice uno de sus estudiosos: "[...] desde la integralidad de los aprendizajes, warisata fue aula, taller, chacra, y ulaka al mismo tiempo". (REYES, 2012, p. 19).

En esta tradición de la educación popular integral y la propuesta de desarrollar pedagogías y metodologías en coherencia con esa tradición, se inscribe el Padre José María Vélaz, fundador del movimiento Fe y Alegría, de origen católico, quien afirmaba: "[El] objetivo primordial de Fe y Alegría [es] contribuir a lograr la transformación social por medio de la Educación Popular Integral; impulsar la justicia social y la justicia estructural por la auto-transformación del pueblo cada vez más educado." del movimiento Nueva Cultura en Brasil, que agrupó múltiples expresiones

6 SALAZAR, C. Warisata mía. La Paz, 1983. También: Elizardo Pérez, precursor de la liberación del indio. La Paz, 1992. Otro de los artistas más reconocidos, Mario Alejandro Illanes, es confinado al trópico y su obra destruida por la dictadura de Toro. Entre sus obras figuraba "La tragedia del pongo", en relación al cierre de la escuela de warisata, en donde habían varios murales de su autoría.

7 VÉLAZ, J. M. (s/f). En: CARRASCO. XV y XVI Congresos Internacionales FIFYA, 2008, p. 12 . 
sociales y culturales del nordeste brasilero, con incidencia en su país, América Latina y el mundo.

Para Freire, la orientación de su educación y pedagogía va a estar marcada por esa dedicatoria de su texto La pedagogía del oprimido: "A los desarrapados del mundo y a quienes descubriéndose en ellos, con ellos sufren y con ellos luchan”. (FREIRE, 1983, p. 23). Allí la educación va a ser entendida como una praxis liberadora, tanto para el opresor como para el oprimido, y en ese mismo texto rescata a Franz Fanon, para hablar de la "zona del no ser"; de allí deriva en cómo el oprimido introyectó al opresor, lo cual va a marcar como concepción política a su propuesta pedagógico-metodológica, en donde quienes participan aprenden a escribir su vida como autores de ella.

En esta perspectiva, su propuesta metodológica se va a desarrollar a partir de la lectura de la realidad, en la cual emerge otro entendimiento del mundo, la del dominado, que reconstruye subjetividades y reconoce su lugar en el contexto y en la historia, ahora como actor de liberación. Es ahí que la pedagogía se adjetiva con la palabra "liberación", ya que está orientada a construir esas nuevas relaciones y le exige implicarse para transformar las condiciones que han creado esa condición de opresión tanto a opresores como a oprimidos, lo cual hace que cualquier proceso de cambio sea profundamente pedagógico para los dos.

En este sentido, la pedagogía freireana tiene como fundamento el diálogo de saberes, un diálogo crítico y liberador en cuanto lo es para una acción de quien participa en los procesos educativos que además de hacer una lectura crítica de la realidad debe contener acciones transformadoras de ella. El camino que inicia el oprimido (o el opresor) para romper la cultura del silencio diciendo su palabra es un camino político, de un aprendizaje desde su lectura del mundo, en donde encuentra las claves para su transformación, pasando de una conciencia ingenua en donde no se separa lo político de lo pedagógico a una transitiva y crítica, haciendo a la pedagogía sustancialmente política como parte de un ejercicio de un mundo sin oprimidos ni opresores, ya que el ejercicio educativo va a permitir la liberación de todos, por lo cual se va a desarrollar como una pedagogía de la libertad, "liberadora" del oprimido y del opresor.

La pedagogía de la liberación como pedagogía de praxis está fundada en el diálogo de saberes, en donde el conjunto de participantes en los procesos de educación popular, leyendo su vida y escribiéndola en su significado de claves y sentidos le permite reconocerse como un ser humano que sabe diferente a otros y que desde su saber puede nombrar el mundo, en su diferencia y construir sentidos y apuestas por hacer el mundo diferente. Una toma de conciencia para ser sujeto con otros oprimidos y ser parte de la humanización del mundo, en donde no es posible tener representaciones de la opresión que no estén enmarcados en los supuestos básicos de la cultura y la sociedad en la que el oprimido está inmerso. 
Por ello, cuando se disponen las herramientas (dispositivos, instrumentos, didácticas, dinámicas participativas, entre otros) con las cuales se hace la práctica pedagógica, éstas implican un ejercicio de ruptura y reelaboración con las existentes en otras propuestas metodológicas. Allí encontramos, por ejemplo, la investigación del universo vocabular, la organización en círculos de cultura como forma física del espacio de encuentro que significa esa manera cómo se reconoce la importancia de cada participante, con la problematización por la cual codifican la realidad en símbolos, la no jerarquización del encuentro en el cual se realiza la codificación y decodificación que va a permitir ir más allá del sentido vocabular para reconocerse en su contexto, historia, desde un diálogo crítico y liberador.

Como lo afirma el propio Freire sobre las lecturas del contexto:

También por eso es que enseñar no puede ser un simple proceso, como he dicho tantas veces, de transferencia de conocimientos del educador al aprendiz, transferencia mecánica de la que resultará memorización mecánica que ya he criticado. Al estudio crítico corresponde también una enseñanza crítica, que necesariamente requiere una forma crítica de comprender y de realizar la lectura de la palabra y la lectura del mundo, la lectura del texto y la lectura del contexto. (FREIRE, 1998, p. 52).

Ello implica la acción transformadora en un ejercicio donde la pregunta se convierte en un dispositivo central para permitir esa lectura cuestionadora del mundo, lo cual le va a permitir enunciar de quiénes se diferencia y por ello acuña el término de "educación bancaria" para dar cuenta de los procesos educativos que a través del control organizan no solo desde los contenidos sino también desde sus metodologías los procesos educativos realizados por la hegemonía y la opresión, a los cuales toda la propuesta de la pedagogía del oprimido se presenta como una respuesta y alternativa. Esto hace visible cómo la pedagogía y la metodología son profundamente políticas, haciendo visible que se puede tener un discurso políticamente de izquierda y procesos pedagógicos y metodológicos de derecha.

Encontraremos desarrollos posteriores en otros textos de Freire que sobrepasan las pretensiones de este escrito. De igual manera, pudiéramos ir mostrando cómo a partir de los años 70 la educación popular fue llegando a distintos territorios, actores y sujetos, y allí fue tejiendo propuestas pedagógicas específicas a manera de geopedagogías, en las cuales los fundamentos de ellas, al tener como punto de partida la lectura crítica de la realidad, van encontrando 
los caminos de esas múltiples pedagogías que se entretejen y se van haciendo específicas según las particularidades, que permiten la relectura y la reinvención de sus procesos y metodologías ${ }^{8}$.

Allí emerge para los educadores populares un campo de actuación en los diversos niveles - micro, meso y macro - como espacios de disputa de poder, control y saber, lo cual coloca al orden del día lo político-pedagógico, en cuanto éste no se hace como tal por un discurso crítico que lo acompañe, sino por la manera como en todo su ejercicio construye relaciones sociales con intereses específicos. En ese sentido, los dispositivos que se utilizan en cada actividad educativa y pedagógica marcan el horizonte político del educador, es decir, él transforma la sociedad desde el cotidiano de su actuación como educador, y ahí el reconocimiento de cómo el poder está en su actuar concreto lo lleva a autocriticarse, en el sentido que lo político no es solo el horizonte emancipador de su discurso, sino también la manera como anticipa la nueva sociedad en su cotidiano pedagógico a través de los dispositivos que usa, haciendo presente que no hay acción humana y educativa exenta de ser política9.

Desde esta mirada la pedagogía en la educación popular se sigue constituyendo a partir de esos troncos básicos y desde las especificidades de sus ámbitos y contextos, lo cual a su vez va a permitir producir nuevos contenidos emancipatorios. Esto es muy visible por ejemplo en su relación con los movimientos sociales, en donde es moldeada por la especificidad de los grupos, por ejemplo, de derechos humanos, de mujeres, de afros, de salud, de comunicación, de personas lesbianas, gays, bisexuales, transexuales e indefinidas (LGBTI), de indígenas, de personas desplazadas y muchos otros, abriendo un amplio campo que muestra cómo sigue en reconstitución esa pedagogía.

Ésta se hace específica según actores y ámbitos de realización, la cual debe ser resuelta desde esas particularidades en donde las opresiones toman forma de etnia, género, sexualidad, lingüística, epistémica, conceptual, dando forma a las nuevas desigualdades y cómo el encuentro con su acumulado le permite descubrir esa diversidad de caminos que ha construido un tronco común con múltiples derivaciones que debe seguir siendo profundizado y elaborado.

Las búsquedas inauguradas desde los movimientos sociales y sus particularidades de inequidad, opresión y dominación fueron construyendo en la educación popular la necesidad no solo de cuestionar la educación que se brindaba para el mercado soportado sobre los estándares y las competencias de un homo

8 Para ver esos múltiples desarrollos remito a mi texto: Educaciones y pedagogías críticas desde el sur. Cartografías de la educación popular. Bogotá: Editorial Magisterio, 2013.

9 VILLA, H. Sistematizar para saber, devenir y resistir. Sistematizando la sistematización de ha-seres de resistencia con vos y con voz en la Corporación Combos. Tesis de grado CINDE, 2015. 
faber constituido solo para la producción económica, y volver a encontrar los ejes de la integralidad de lo humano para estos tiempos, por lo cual se inicia un camino de elaboración propia sobre las capacidades entendidas estas como la potencia de lo humano y su ampliación en el marco del buen vivir.

Uno de los asuntos centrales en la configuración de la educación popular se refiere a la manera como se ha venido constituyendo con fuerza y especificidad en las diferentes manifestaciones de la socialización, así como en los variados procesos educativos formales, no formales e informales, desarrollando un diverso repertorio de propuestas metodológicas en coherencia con su apuesta pedagógica de negociación cultural y diálogo y confrontación de saberes, convirtiendo sus herramientas en dispositivos de saber y poder. Esa variedad ha llevado a que éstas no sean universales ni simplemente procedimientos técnicos, sino elementos para construir los empoderamientos de sujetos, actores, organizaciones y movimientos.

\section{Decantando el acumulado pedagógico}

El proceso de construcción de la educación popular es marcado por una tradición que intenta dar lugar a lo otro negado y convertir sus intereses y necesidades en una apuesta para toda la sociedad, en cuanto le propone a todas las educaciones y a todos los educadores y educadoras que intentan desde su práctica construir sociedades más justas que reconocen la diversidad fundada en la diferencia, y que a través de procesos educativos enfrentan la desigualdad y por medio de ello buscan transformar los mundos donde actúan, lo cual se hace presente en un ejercicio de justicia educativa que está presente en todas sus prácticas tratando de hacer la historia desde ese otro punto de vista, lo otro negado.

Esa diferencia que hace visible la diversidad, en la esfera de lo pedagógico tomó en un primer momento el camino de enfrentar la propuesta del lancasterianismo que había sido asumida por las élites criollas para las escuelas de las repúblicas nacientes desde la crítica de Simón Rodríguez; luego toma la forma de educación propia a partir de cosmogonías negadas y visibilizadas en el proyecto pedagógico de warisata y que en la tradición freireana de la educación popular se constituye desde el diálogo de saberes, en el cual el educando enuncia su mundo y sale del silencio. Allí hace visible la existencia de saberes que tienen fundamentos culturales, epistémicos y conceptuales basados en la diferencia, pero que en las particularidades del conocimiento, epistemología y cultura de la modernidad eurocéntricos hacen que al hablar de saberes y el diálogo respectivo 
estemos frente a una diversidad en desigualdad y subalternidad, un intercambio político entre poderes epistémicos diferentes.

En ese sentido, si bien el diálogo de saberes al realizarse en condiciones de subalternidad, en donde lo local y las culturas no desarrolladas en la lógica del conocimiento occidental y de la modernidad, son subsumidas, controladas y en ocasiones descalificadas, hace que el mismo opere en dinámicas y procesos donde se da lugar a la interculturalidad con lo diferente, dando forma a la confrontación de saberes, muy visible en los momentos en los cuales en ese diálogo emergen visiones antagónicas. Por ejemplo, el paradigma antropocéntrico del desarrollo capitalista y el biocéntrico del buen vivir de las cosmogonías originarias.

Reconocer la confrontación permite a su vez construir las posibles dinámicas de complementariedad en un mundo con pluralismo epistémico, en el sentido que enuncia Gramsci (1972) cuando muestra que las relaciones de saber obedecen a relaciones de confrontación, hegemonía y subalternidad. De igual manera, en cuanto la educación popular propone la transformación de las realidades que producen opresión, desigualdad, dominación, implica una reflexión para la acción emancipadora, de sí, de la vida y de la sociedad a través de sus diferentes ámbitos de actuación. En ese sentido, el diálogo-confrontación de saberes requiere una negociación cultural que constituye las bases comunes para la acción.

Entendido así, estamos en un proceso que no es lineal, sino que las tres dinámicas de saber y conocimiento se dan en los procesos de forma simultánea y debe utilizar dispositivos pedagógicos (didácticas, herramientas, instrumentos, dinámicas de grupo, etc.), en coherencia con las dinámicas de saber y poder que las constituyen y se busca construir haciendo del ejercicio educativo un acto de empoderamiento. En esta perspectiva, la comprensión de las tres dinámicas pedagógicas, diálogo de saberes, confrontación de saberes y negociación cultural, las pudiéramos fundamentar como sigue.

\section{Diálogo de saberes}

En su visión primigenia, se refiere al diálogo de los participantes en un círculo de cultura para lograr romper el silencio y hacer que emerjan las voces que harán el paso de una conciencia ingenua a una transitiva y crítica y a través de ello construyan su realidad desde el lenguaje en una actividad en donde quien acompaña estos procesos replantea la educación bancaria y la autoridad cognitiva que soporta para convertirse en un mediador cultural que sabe que va 
al acto educativo como un aprendiz, en donde sabe escuchar, sabe desaprender y se reconoce en la diferencia de cosmogonías haciendo real que todo el que enseña aprende y el que aprende enseña ${ }^{10}$.

Para hacer real este proceso reconoce que la diversidad y lo diferente deben expresarse como mundos llenos de significados y que en su emergencia permiten reconocer las desigualdades y opresiones que se constituyen en sus particulares formas de vivir su vida en sus territorios y localizaciones. Por ello, el diálogo de saberes es la posibilidad de enunciar el mundo propio, reconociéndolo, valorándolo en su carácter contradictorio, haciendo realidad una intraculturalidad en donde aclaro y enuncio mi mundo desde el pre-supuesto de una equivalencia entre cosmogonías con su expresión de múltiples saberes y las cosmogonías como expresión de conocimientos y saberes disciplinarios y disciplinados. (KUSCH, 1977).

Un interesante desarrollo del sentido del diálogo se encuentra en los trabajos del educador popular chileno Rolando Pinto (2014), quien muestra un diálogo de saberes que se constituye bajo el presupuesto pedagógico de una equivalencia entre saberes y conocimientos, en donde los modos de la vida regida por ellos ha construido comunidades de sujetos que viven en esa comprensión del mundo, el cual al ser explicitado hace visible profundas diferencias epistémicas, que exigen un especial cuidado en el diálogo.

El principio de la equivalencia de culturas y cosmovisiones exige unos desaprendizajes de las maneras tradicionales, de las expresiones de esos saberes y conocimientos en cuanto las formas dominantes de ellas a través de los procesos escolarizados llevan cientos de años constituyéndose, y en ese sentido han hecho fuerte una lógica de ellas que los hace refractarios al reconocimiento de los saberes si no es en una lógica de minoría o como una forma inferior del suyo, o bien como un posicionamiento no epistémico en su modernidad. Esas diferencias de poder hacen visible cómo el diálogo de saberes no es un ejercicio didáctico sino un dispositivo que pone en tensión de la manera cómo los supuestos de las cosmovisiones siempre están implícitos, y con contadas excepciones se cuestionan.

Por ello hablar de confrontación de saberes es dar cuenta de ese ejercicio de poder en el orden de expresión de la realidad, desde múltiples realidades cognitivas y de las múltiples maneras en las cuales los discursos hegemónicos explicitan esas epistemes únicas.

10 Dimensión educativa. El diálogo en la educación. Perspectivas teóricas y propuestas didácticas. Revista Aportes, Bogotá, n. 53, 2000. 


\section{Confrontación de saberes}

La premisa inicial de este proceso se da en la interlocución entre los diferentes participantes en una actividad educativa desde la perspectiva pedagógica y metodológica de la educación popular, y ello está presente en los dispositivos que muestran cómo las diversas concepciones sobre los asuntos trabajados y la manera cómo ellos y sus discursos que la fundamentan han sido constituidos por procesos de etnia, género, edad, clase social, dando forma a una interculturalidad desde múltiples concepciones, que bajo el principio de complementariedad van construyendo la riqueza de la diversidad y la singularidad para construir esos caminos variados para otros mundos posibles.

Es muy visible ese paso de la intraculturalidad propiciada por el diálogo de saberes a la interculturalidad, dinamizada por la confrontación de saberes en el momento en el que lo otro es negado a nombre de lo universal, los saberes a nombre de la ciencia, lo comunitario a nombre del individuo y lo personal, lo multicultural a nombre de lo monocultural, los sentidos a nombre de la razón y muchos otros dualismos que el poder ha instituido para negar o invisibilizar lo otro y forjar redes invisibles de interlocución y negación, construyendo exclusiones sobre otras epistemologías que no responden a su universalidad, generando lo que algunos han denominado "epistemicidios". (SANTOS, 2009).

Esa confrontación de saberes y conocimientos nos habla precisamente de la manera como enfrentamos y buscamos superar las exclusiones epistemológicas, haciendo real que la interculturalidad es una construcción contextual, histórica, política, social y de poderes en disputa, y por lo tanto, también construida sobre desigualdades que al negar no dan lugar a la interlocución con la diversidad, construyendo una manera monológica de las culturas en los aspectos del saber y del conocimiento. Por ello, metodológicamente va a ser un ejercicio de colocar con fuerza propia desde sus narrativas y epistemes, aquellos asuntos negados y desafirmados, que el diálogo de saberes ha logrado colocar en un escenario de intraculturalidad.

Este ejercicio metodológico permite a la vez que empodera a las diversas formas dominadas, les exige encontrar la diferencia y construir con rigor lo propio para visibilizar los antagonismos en los cuales se diverge en la construcción de otros mundos posibles, en su entendimiento de la naturaleza, la sociedad, la cultura y desde luego, la acción transformadora de ellas propuesta por la educación popular. 


\section{Negociación cultural}

La educación popular no solo busca saberes y conocimientos propios en tiempos paradójicos, sino que los trabaja en un proceso de complementariedad con las concepciones, cosmovisiones, y cosmogonías de quienes buscan construir otros mundos sin explotación ni opresión, y que, reconociendo la pluriculturalidad, transforman los mundos en los que actúan, micro, meso y macro, de quienes se reconocen en alguno de los ámbitos de ella (individuación, socialización, articulación a lo público, vinculación a organizaciones y movimientos, articulación a procesos gubernamentales o masivos) y allí hace negociaciones culturales para encontrar lo común, que va a ser posible al coincidir con los grupos y las personas con los cuales se emprenderá la acción transformadora en los diferentes campos donde se actúa.

En ese sentido, la negociación va a ser ese ejercicio a través del cual se decantan las comunidades epistémicas y de saber y conocimiento a través de las cuales se reconocen como comunidades de aprendizaje permanentes para darle forma y vida a una masa crítica de variadas tradiciones con las cuales en el ejercicio de diálogo-confrontación-negociación constituimos las comunidades de acción y transformación que harán real la equivalencia de culturas, cosmovisiones y cosmogonías para desde esa práctica concreta construir concepciones más integrales de la vida, sin dicotomías, buscando darle lugar a un mundo donde según las miradas del buen vivir/vivir bien: "todo es vida, uno es todo y todo es uno”. (IBÁÑEZ; AGUIRRE 2013, p. 28).

\section{Algunas notas de cierre}

La pedagogía de la educación popular se constituye en un ejercicio no lineal de diálogo de saberes que da forma a la intraculturalidad, confrontación de saberes que gestan las dinámicas de interculturalidad, y negociación cultural que gesta los procesos de transformación basados en acuerdos y elementos comunes, forjando la transculturalidad.

En el ejercicio de confrontación de saberes, se hacen visibles las reales condiciones de interlocución y de igualdad epistémica, permitiendo confrontar lo que niega y haciendo visible su propio rigor y trazando puentes para optimizar y fundamentar las múltiples diversidades. Allí el diálogo de saberes se hace 
político, en cuanto encuentra los sistemas de poder que descalifican y excluyen saberes y conocimientos, y da lugar en la confrontación a esa posibilidad de dotar de un estatuto propio desde las sabidurías, prácticas, cosmogonías, permitiendo una contrastación que no solo busca construir la complementariedad sino hacer visible ese intercambio desigual entre culturas, lo cual va a permitir la emergencia de esos saberes y conocimientos propio de lo subalterno.

La negociación cultural nos permitirá construir las representaciones y construcciones desde prácticas compartidas en las más variadas tradiciones y que hoy se manifiestan en una articulación que hace posible un pluralismo epistemológico crítico que nos habla de la manera como en estos tiempos construimos sentidos, significados desde la complementariedad, enfrentando cualquier matriz epistémicamente homogeneizadora, abriéndonos a un mundo biodiverso donde se elabora y reelabora un campo más amplio que la propuesta antropocéntrica.

Esta construcción de otro escenario bio-cultural, en donde los saberes y conocimientos están vivos y son recreados dando forma a una reelaboración de creencias, conocimientos, costumbres, saberes, desde otros diferentes, que al dialogar, confrontar, negociar, se convierten en constructores de mundos en una inclusión en todos los sentidos, de todas las subjetividades, de todos los conocimientos y saberes que le apuestan a seguir construyendo y transformando el mundo desde la diferencia.

Por fin, ese acumulado hoy ha consolidado una reflexión que permite hablar de una propuesta educativa para toda la sociedad con fundamentos conceptuales, políticos, pedagógicos, metodológicos, epistemológicos y que hacen posible una práctica de un ejercicio educativo que integra intraculturalidad, interculturalidad y transculturalidad y que teje lo común para seguir apostándole a la transformación de los mundos desde el reconocimiento de que somos humanamente diferentes, culturalmente diversos y seguimos viviendo en sociedades profundamente desiguales.

\section{REFERENCIAS}

BOFF, L. Evangelio del Cristo cósmico. Madrid: Editorial Trotta, 2009.

BOLÍVAR, S. Discurso ante el Congreso de Angostura el 15 de febrero de 1819, día de su instalación. Disponible en: $<$ https://es.wikisource.org/wiki/Discurso_de_Simón_Bolívar_ante_el_Congreso_de_Angostura $>$. Acceso en: 16 ago. 2016.

DUSSEL, E. Filosofía de la liberación. Bogotá: Nueva América, 1996. 
FREIRE, P. Pedagogía del oprimido. México: Siglo XXI Editores, 1983.

FREIRE, P. Cartas a quien pretende enseñar. México: Siglo XXI Editores, 1998.

GRAMSCI, A. La filosofía de la praxis. México: Nueva Imagen, 1972.

IBÁÑEZ, A.; AGUIRRE, N. Buen vivir/Vivir bien. Una utopía desde el Sur. Bogotá: Desde Abajo, 2013.

KUSCH, R. El pensamiento indígena y popular en América. Buenos Aires: Hachétte, 1977.

MACLAREN, P. El Che Guevara, Paulo Freire y la pedagogía de la revolución. México: Siglo XXI Editores, 2008.

MARTÍN-BARBERO, J. De los medios a las mediaciones. Barcelona: Gustavo Gili, 1987.

MEJÍA, M. R. La educación popular del siglo XXI. Una resistencia intercultural desde el sur y desde abajo. Bogotá: Desde Abajo, 2015. (Colección Primeros Pasos).

PÉREZ, E. Mensaje de la escuela de warisata en el día de las Américas. La Paz, 1934.

PÉREZ, E. La escuela ayllu de warisata. La Paz: Papeles, 1985.

PINTO, R.; OSORIO, J. (Col.). Pedagogía crítica para una educación pública y transformadora en América Latina. Lima: Derrama Magisterial, 2014. (Colección Cooperación con la formación docente en América Latina, v. II).

PUIGGRÓS, A. La educación popular en América Latina. México: Nueva Imagen, 1984.

QUIJANO, A. Colonialidad del poder, eurocentrismo y ciencias sociales. Perspectivas latinoamericanas. Buenos Aires: CLACSO, 2000.

REYES, J. (Ed.). Proceso Educación y pueblo (1900-2010). Bolivia, algunos referentes experienciales y documentales. La Paz: CAS - Red feria - UMSA - CEE - CEBIAE, 2012.

RODRÍGUEZ, S. Luces y virtudes sociales. Caracas: Monte Ávila Editores, 1992. En: RODRÍGUEZ, S. Obras completas. Caracas: Universidad Simón Rodríguez, 1975. T. II.

SALAZAR, C. Warisata mía. La Paz, 1983.

SANTOS, B. de S. Una epistemología del sur. La reinvención del conocimiento y la emancipación social. México: Siglo XXI Editorial: CLACSO, 2009.

Texto recibido en 16 de junio de 2016.

Texto aprobado en 16 de junio de 2016. 
